\title{
El giro pragmático de Rorty *
}

\author{
JÜRGEN HABERMAS \\ Johann Wolfgang Goethe-Universität, Frankfurt
}

El artículo examina la concepción neopragmatista desde la cual Rorty defiende una concepción antirrcalista del conocimiento. A fin de evaluar si es correcta la radicalización del «signo lingǘstico» emprendida por el autor estadounidense, se compara la problemática contextualista con la duda epistemológica del escéptico moderno y se analiza el problema tradicionalmente ligado a las concepciones de la verdad como coherencia que subyacen a los planteamientos contextualistas - de cómo distinguir la verdad de la aceptabilidad racional. Ante esta cuestión las opiniones se dividen: mientras que Rorty asjmila verdad y justificación al precio de sacrificar la intuición realista cotidiana, otros autores intentan dar cuenta de esta intuición desde dentro del paradigma lingüistico, ya sea mediante una deflación de la problemática de la verdad o mediante una idealización del proceso de justificación mismo. El autor reacciona frente a ambas posiciones: por un lado, contra un deflacionismo que se apoya en el concepto semántico de verdad, hace valer aquí una posición pragmática; por otro, desde esta misma óptica, critica un tipo de epistemologización del concepto de verdad que él mismo había defendido hasta el momento. Por esta vía se articula una alternativa frente a la liquidación de las pretensiones de verdad incondicionales que ha llevado a Rorty a una naturalización de la razón lingüistica muy problemática.

En Trotsky y las orquídeas silvestres Rorty lanza una mirada romántica a su evolución filosófica. En forma de un «relato de iniciación" presenta su proceso de formación como la disolución gradual del sueño del adolescente que aspiraba a fundit en una sola imagen la extraordinaria belleza de las orquídeas silvestres con la liberación de la sociedad atormentada de su dolor profano - - to hold reality and justice in a single vision» (Yeats)-.. El trasfondo existencial del neopragmatismo de Rorty cstá constituido por la rebelión frente a las falsas promesas de una filosofía que, con lo teórico, pretende poder dar satisfacción a necesidades tanto estéticas como morales. En su momento, la metafísica buscaba iniciarnos en el ejercicio de una purificadora contemplación de lo bueno y de lo bello. Pero el joven Rorty, que se entusiasmó con Platón, Aristóteles y Tomás de Aquino, pasa por la dolorosa experiencia de comprobar que aquel contacto a la vez extasiante y reconciliador con la realidad de to extraordinario que prometía la teoría, en el mejor de los casos sólo puede alcanzarse mediante las formas más sólidas de oración, pero no por vía filosófica.

* Traducción de Perc Fabra. 
Rorty recuerda a continuación aquel Dewey denostado por McKeon, Leo Strauss y Mortimer Adler y que en el Chicago de finales de los años cuarenta todavía no había sido totalmente olvidado. La convicción de que más allá de la realidad de lo cotidiano no se escondía otra realídad superior ni se ocultaba ningún «ente en sí» que tuviera que descubrirse por arrebato extático y de que la praxis no dcja espacio para ninguna visión salvifica, cura al desilusionado de la enfermedad platónica — sin que, por lo demás, consiga extinguir totalmente aquel recuerdo de la visión exótica y el aroma turbador de las orquídeas silvestres en las montañas de su infancia, al noroeste de Nueva Jersey.

Más o menos de esta forma nos cuenta hoy Rorty los motivos vitales que le llevaron a su idea — que desarrolla en Contingencia, ironía y solidaridaddel doble reinado de Dewey y Heidegger.

Curiosamente esta autopresentación no contiene ninguna referencia al extraordinario papel de Wittgenstein, cl tercero del grupo. La exposición de sus experiencias de formación filosófica se trunca precisamente con aquellas lecturas de Hegel, cuando llega a su fin el período de estudio en Yalc e inicia la labor de filósofo profesional. El estudio y práctica de la filosofía analítica con Wilfrid Sellars, su auténtico maestro, la fundamental convicción fisicalista, la triunfante carrera del joven analítico, ni tan sólo se mencionan. Pero sólo la ambivalencia frente a esta tradición, la única en cuyo lenguaje Rorty aprendió a argumentar y en la que ha desarrollado hasta hoy sus provocativas teorías, puede explicar por qué no atribuye ninguna significación —en términos de crítica cultural- a su giro antiplatónico.

Antes de concentrarme en los fundamentos de la concepción neopragmatista, consideraré brevemente la causa de este modo de filosofar que querría suprimirse a sí mismo en cuanto tal (I). A partir de la radicalización pragmática del giro lingüístico, Rorty llega a una comprensión antirrealista del conocimiento (II). Para examinar si radicaliza el giro lingüístico de forma correcta compararé después la problemática contextualista con la duda epistemológica del escéptico moderno (III) y recordaré un problema que siempre estuvo ligado con las concepciones de la verdad como coherencia: cómo hay que distinguir la verdad de la aceptabilidad racional (IV). Ante este problema las opiniones se dividen. Mientras que Rorty asimila verdad y justificación al precio de sacrificar la intuición realista cotidiana, otros intentan dar cuenta de esta intuición también dentro del paradigma lingüístico, ya sea con la ayuda de una deflación de la problemática de la verdad o mediante una idealización del proceso de justificación mismo. Por un lado, contra un deflacionismo que se apoya en el concepto semántico de verdad, hago valer una posición pragmática (V); por otro lado, desdc esta óptica, critico un tipo de epistemologización del concepto de verdad que en su día yo mismo defendí (VI). Por esta vía desarrollo una alternativa frente a aquella liquidación de las pretensiones de verdad incondicionales (VII) que ha llevado a Rorty, finalmente, a una naturalización de la razón linguiistizada muy problemática $\mathrm{o}$, cuando menos, cargada de dudosas consecuencias (VIII). 


\section{Antiplatónico por impulso platónico}

Richard Rorty es uno de los más eminentes filósofos analíticos y siempre argumenta de manera informada y precisa. Sin embargo, el esbozo de una filosofia que tendría que acabar con todas las filosofías surge más de la melancolia đc un metafísico desengañado, estimulado por el aguijón nominalista, que no de la autocrítica de un analítico ilustrado que desearía culminar cl giro lingüístico de forma pragmatista. En el año 1967, cuando la filosofía analítica (en sus dos versiones) había conseguido una validez mundial parecida a la que en su día tuvo el neokantismo en tiempos de la I Guerra Mundial, Rorty publicó, con el prometedor y lacónico título de El giro lingǘśtico, una recopilación de artículos de varios autores que, visto retrospectivamente, marcó una cesura en la historia del pensamiento analítico. Los textos allí recogidos tenían que satisfacer un doble objetivo: en tanto que hacían balance definitivo de un triunfante desarrollo, debían señalar al mismo tiempo su final. En cualquier caso, la distancia metafilosófica desde la que el editor comentaba los textos dejaba entrever, aun en gesto laudatorio, el mensaje hegeliano de que toda forma del espíritu que llega a la madurez está condenada, dialécticamente, al ocaso. Rorty dio la señal de salida de un discurso que, entretanto, se ha dotado del nombre de "postanalítico». En la introducción especula sobre un «futuro» de la filosofia analítica que la devuelve a formas del pasado. Frente a una ortodoxia todavía incólume, Rorty señala tres planteamientos que contradicen al unisono el supuesto de fondo de «que hay verdades filosóficas por descubrir quc pueden fundamentarse con argumentos». Y vincula estos planteamientos antiplatónicos a los nombres de Heidegger, Wittgenstein y Waismann (cuyo programa todavía describía Rorty, en aquel momento, de modo parecido a como hará más tarde con el pragmatismo de Dewey).

La contemplación distanciada de la filosofía analítica no disimula en forma alguna el gran respeto de un iniciado que se separa aquí de su propia tradición: "En los últimos treinta años, la filosofía del lenguaje ha conseguido poner a la defensiva a toda la tradición filosófica, desde Parménides a Bradley y Whitchead, pasando por Descartes y Hume. Lo ha hecho mediante un examen meticuloso de las formas en las que los filosofos tradicionales han utilizado el lenguaje al formular sus problemas. Este logro es suficiente para situar este período junto a las grandes épocas de la historia de la filosofía» ${ }^{1}$. Sólo la fuerza irresistible de los argumentos analíticos explica el verdadero pesar de Rorty; es esta fuerza la que hace de la despedida de las promesas de la metafísica algo tan irrevocable que, incluso después de la filosofía analítica, no puede haber ninguna alternativa que conduzca a un pensamiento post-

R. Rorty, The Linguistic Tum. Recent Essays in Philosophical Method, University of Chicago Press, Phoenix Edition, 1970, p. 33. (Hay traducción española de la introducción de Rorty a esta recopilación en R. Rorty, El giro lingüistico, Barcelona, Paidós, 1990.) 
metafísico. Sin embargo, Rorty sigue a la búsqueda de un modo de pensar que, como dice Adorno al final de la Dialéctica negativa, siga siendo «solidario con la metafísica en el momento de su desmoronamiento" ${ }^{2}$. La ironía forzada que propaga hoy Rorty rezuma melancolía: «El intelectual postfilosófico de Rorty es irónico porque se da cuenta de que la verdad no es todo aquello que él habría querido que fuera. La ironía depende esencialmente de una especie de nostalgie de la verité» ${ }^{3}$. Tampoco la división del trabajo romántica entre ironía y seriedad, entre Heidegger y Dewey, puede mitigar aquella aflicción. Dado que la metafísica sólo domina el lenguaje del conocimiento, la estetización de su pretensión de verdad acaba anestesiando la tradición en forma de bien cultural. La realidad de las ideas, con las que nos prometía entrar en contacto la teoría platónica, no es lo mismo que la extraordinaria seducción de la experiencia estética. Lo que una vez había querido ser «verdadero» en sentido enfático, no puede conservarse bajo el modo de lo «sublime». Al perder la perentoriedad de sus juicios, la metafisica pierde también su contenido 4 .

Cuando uno se encuentra ante este dilema resulta comprensible el movimiento que finalmente hace Rorty para devolver a la filosofía, todavía hoy, algo de aquella «teoría», de aquella inimitable combinación de orquídeas silvestres y Trotsky: imitar al menos el gesto de una aprehensión estimulante y al mismo tiempo preñada de consecuencias prácticas. Pero la necesidad metafísica de liberar a la filosofía de la esterilidad de un pensamiento postmetafísico en pequeño formato sólo puede ser satisfecha ya por canales postmetafísicos. La despedida de la filosofía analítica no puede conducir de nuevo a la devaluada metafísica. Por ello lo único que queda es el poner en escena la despedida de la filosofía en general. Sólo si el mismo acto de la despedida desencadenara un auténtico shock y tuviera repercusión en la vida, podría corresponderle a la filosofía, «en el momento de su desmoronamiento", una significación que no fuera meramente académica. Pero una disolución de la filosofía analítica que se ha producido por medios analíticos, icómo podría adquirir la importancia necesaria para que este pensamiento pudiera resplandecer por última vcz con todo el brillo de su gran tradición? Rorty quiere -asi entiendo su impulso por la gran filosofía refractado naturalistamente- responder a esta pregunta.

Rorty muestra, ante todo, que la filosofía analítica comparte una premisa esencial con la tradición que ella misma ha contribuido a devaluar. Se trata de aquella convicción de uque todavía existen verdades filosóficas por descubrir». Gracias a una idea muy alemana que toma prestada de Heidegger,

\footnotetext{
"T, W. Adorno, Negative Dialektik, Ges. Schriften, vol. 6, Francfort del Meno, 1973, p. 400 (Dialéctica negativa, Madrid, Taurus, 1975).

${ }^{3}$ M. Williams, Unnatural Doubts, Princeton U. P., Princeton, N. J., 1996 , p. 365 (n. 51); véase también R. Rorty, «Is Derrida a Quasi-Transcendental Philosopher?», Contemporary Literature, $1995, \mathrm{pp} .173-200$.

"Véase el intercambio entre Th. McCarthy y Richard Rorty en Critical Inquiry, 16, 1990, pp. $355-370$ y $633-641$.
} 
Rorty atribuye a este proton pseudos de la metafísica occidental una carga dramática. Según esta tesis, los logros profanos de Occidente han acontecido en cada caso en el ámbito de una comprensión epocal, precisamente aquella "comprensión del ser» administrada por la metafísica. Sin embargo, después de la filosofía analítica, Rorty ya no puede estilizar un pensamiento postmetafísico en forma de sacra «rememoración del ser», como hiciera Heidegger, sino que concibe la deconstrucción de la historia de la metafísica, en el sentido de Wittgenstein, como un diagnóstico deflacionante. El antiplatonismo extrae una significación eminentemente práctica para la vida sólo de la gravedad de la enfermedad que debe curar. El desenmascaramiento del platonismo apunta, más allá de la filosofía escolar, hacia una cultura enajenada platónicamente de si misma. Si finalmente el acto de la despedida no tiene que agotarse en simple negación, Rorty debe abrir la perspectiva para una nueva autocomprensión que pueda situarse en el lugar de las antiguas, ahora deflacionadas. Para ello reinterpreta el hegelianismo de Dewey de forma que permita abrir los ojos a una praxis cotidiana que no esté ya desfigurada por prejuicios platónicos. Como Hegel, también los «últimos» filósofos vuelven a pensar su tiempo en conceptos.

Naturalmente, Rorty sabe que tales reflexiones metafilosóficas no pueden cambiar por sí solas la autocomprensión de la filosofía ${ }^{5}$. No puede apartarse de la filosofia sin hacer valer sus ideas en ella. Y si Rorty no fuera el filósofo que es -escrupuloso y sensible, productivo y estimulante- se limitaría a jugar el papel retórico del reeducador. Pero incluso el diagnóstico de una falsa autocomprensión continúa siendo una tarea teórica. Rorty debe aportar argumentos para convencer a sus colegas de que la distinción "platónica» entre "convencer" y «persuadir» carece de sentido. Debe mostrar que incluso la filosofía analítica se halla presa en el círculo maldito de la metafísica que ella misma combate.

\section{El giro pragmático}

Con su importante investigación La filosofia y el espejo de la naturaleza (1979) Rorty persigue varios objetivos: en tanto que emprende la deconstrucción de la filosofía de la conciencia quiere completar un giro lingüistico que había quedado inacabado, de forma que quede patente la errónea comprensión platónica que de sí misma tiene nuestra cultura. Mis dudas se refieren al segundo de estos pasos. El giro pragmático que, con razón, Rorty reclama frente a los planteamientos semánticos, ihace realmente necesaria una comprensión antirrealista del conocimiento?

1) El marco conceptual básico de la filosofía del sujeto ha sido sometido a una crítica implacable por parte de Peirce, Wittgenstein y Heidegger. Rorty utiliza argumentos contemporáneos (entre otros, de Sellars, Quine y Davidson),

"Rorty (1970), p. 39. 
para poner en evidencia —con propósitos de crítica de la razón- los supuestos de fondo mentalistas de la teoría del conocimiento. Las ideas de kautoconciencia» y «subjetividad» implican que el sujeto cognoscente, cuando no se orienta directamente a los objetos sino que se dirige de un modo reflexivo a sus propias representaciones de éstos, puede abrir una esfera privilegiada de vivencias inmediatamente accesibles y absolutamente ciertas. La separación entre lo interno y lo externo -es decir, un dualismo de mente y cuerpo que apela al acceso privilegiado de la primera persona a sus propias vivenciases constitutiva para la teoría clásica del conocimiento. La autoridad epistémica de la primera persona se nutre de las fuentes de tres supuestos que conforman todo un paradigma:

- que conocemos nuestros estados mentales mejor que todo lo demás;

- que el conocer se produce esencialmente bajo el modo de la representación de objetos, y certeza.

- que la verdad de los juicios se apoya en evidencias que garantizan la

El análisis de la forma lingüística de nuestras vivencias y pensamientos descubre en cada uno de estos supuestos su mito correspondiente -el mito de lo dado, el mito del pensamiento representacionista y el mito de la verdad como certeza - Se muestra que no es posible pasar por detrás de la expresión lingüistica como medio de exposición y comunicación del saber. No hay experiencias sin interpretar que sean accesibles sólo privadamente y que se sustraigan al enjuiciamiento público o a la corrección. El conocimiento de objetos no es modelo suficiente para el saber de estados de cosas articulados proposicionalmente. $Y$ la verdad es una propiedad que los enunciados criticables no pueden perder; dicha propiedad sólo puede justificarse mediante razones, y no puede acreditarse mediante la géncsis de las representaciones.

Pего Rorty liga esta crítica del mentalismo al objetivo más profundo de radicalizar el giro linguístico. Quiere mostrar aquello «en lo que se convierte la filosofía del lenguaje cuando uno se abstiene, de una vez por todas, de imitar con ella a Kant y Hume» ${ }^{\hbar}$. Mientras la relación sujeto-objeto es proyectada simplemente a la relación oración-hecho, las respuestas semánticas permanecen prisioneras de las problemáticas mentalistas. En la medida en que la exposición (Darstellung) de estados de cosas, así como la representación (Vorstellung) de objetos - ambas cosas se llaman en inglés representationsigue concibićndosc como una relación bivalente, el giro lingüistico deja intacto el kespejo de la naturaleza» como metáfora del conocimiento del mundo.

Rorty quiere agotar el espacio conceptual abierto por la filosofía del lenguaje. Sustituye, con Peirce, la relación bivalente entre sujeto representador y objeto representado por la rclación trivalente de la expresión simbólica que cstablece

${ }^{6}$ R. Rorty, Der Spiegel der Natur, Francfort del Meno, 1981, p. 287 (La filosofia y el espejo de la naturaleza, Madrid, Cátedra, 1983). 
un estado de cosas para una comunidad de interpretación. El mundo objetivo deja de ser algo a representar, es sólo el punto de referencia común de un proceso de cntendimiento entre miembros de una comunidad de comunicación que se entienden unos con otros sobre algo. Los hechos comunicados no pueden separarse del proceso de comunicación, del mismo modo que la presuposición de un mundo objetivo no puede separarse del horizonte interpretativo intersubjetivamente compartido en el que ya sicmpre se mueven los participantes en la comunicación. El conocimiento no se produce ya en la correspondencia de las oraciones con los hechos. Por eso, sólo el giro lingüístico llevado consecuentemente hasta el final puede superar, junto con el mentalismo, el modelo epistcmológico del espejo de la naturaleza.

2) Lo que me interesa es la cuestión de si Rorty emprende de forma correcta la plausible ampliación pragmática del giro lingüístico. Si dejamos de remitir las cuestiones epistemológicas sólo al lenguaje como forma gramatical de exposición y las remitimos, en cambio, al uso comunicativo del lenguaje, se abre la dimensión más amplia de la red de interacciones y tradiciones comunes, es decir, el espacio público de un mundo de la vida intersubjetivamente compartido por aquellos que utilizan un mismo lenguaje. La perspectiva ampliada hace visible la conexión interna entre los rendimientos cognitivos y los procesos de cooperación y entendimiento de los individuos socializados: «Pongamos la comunicación, el diálogo entre personas, en el lugar de la confrontación, del estar frente a frente de personas y estados de cosas, y podremos prescindir así del espejo de la naturaleza» ${ }^{7}$. El modelo epistemológico "de la comunicación» permite comprender que no tenemos ningún acceso inmediato a entidades en el mundo que sea independiente de nuestras prácticas de entendimiento y del contexto lingúísticamente constituido de nuestro mundo de la vida: "Elementos de lo que llamamos "lenguaje" o "mente" penetran tan profundamente en lo que llamamos "realidad" que el auténtico proyecto de representarnos a nosotros mismos como "cartógrafos" de algo "independiente del lenguaje" está desde el principio fatalmente condenado al fracaso.»

Ésta es una formulación de Hilary Putnam que Rorty acepta ". Sin embargo, Rorty tiene en mente algo distinto al «realismo interno», que destaca que las condiciones de objetividad del conocimiento sólo pueden analizarse en relación con las condiciones de intersubjetividad de un entendimiento sobre lo dicho. Según la concepción de Rorty el «estar en contacto con la realidad» debe traducirse en términos del «estar en contacto con una comunidad humana», de tal manera que desaparece totalmente aquella intuición realista a la que el mentalismo quería hacer justicia con el espejo de la naturaleza o con la correspondencia entre representación y lo representado. Para Rorty todo tipo

'Rorty (1981), p. 191.

" H. Putnam, Realism with a Human Face, Harvard U. P., Cambridge, Mass., 1990, p. 28; R. Rorty, «Putnam and the Relativist Menace», The Joumal of Philosophy, XC, septiembre 1993, p. 443 , 
de representación de algo en el mundo objetivo es una ilusión peligrosa. Ahora bien, es totalmente acertado que con el giro pragmático la autoridad epistémica de la primera persona del singular que inspecciona su interior se traslada a la primera persona del plural, a saber, al "nosotros" de una comunidad de comunicación ante la cual cada uno justifica sus propias ideas. Pero es la interpretación empirista de esta nueva autoridad lo que conduce a Rorty a equiparar el "saber" con aquello que es aceptado en cada caso como «racional» según los criterios de nuestra comunidad.

De la misma forma que Hume y Locke habían referido sus reflexiones mentalistas a la conciencia de personas empíricas, Kant las había remitido a la conciencia de personas uen general». Tambiên las reflexiones lingüísticas pueden remitirse a comunidades de comunicación ken general». Pero Rorty, el nominalista, se halla en la tradición empirista y relaciona la autoridad epistémica con la praxis social habitual de «cada una de nuestras» comunidades. Considera un sinsentido «ver en nuestras prácticas sociales de justificación algo más que simplemente tales prácticas» ${ }^{9}$. El mismo Rorty establece el nexo entre, por un lado, la interpretación contextualista del giro pragmático y la comprensión antirrealista del conocimiento y, por otro, el rechazo de una estrategia kantiana de análisis ${ }^{10}$ : «Si se considera el conocimiento, no como el empeño en representar la naturaleza, sino como dependiente de la práctica lingǘstica y del entorno social, es de esperar que abandonemos la idea de una metapráctica que aporte una crítica de todas las formas posibles de práctica social»" "Un intento pragmático-formal de este tipo sería para Rorty una recaída en el fundamentalismo. En el siglo xvI los conceptos fundamentales de subjetividad y autoconciencia propios de una filosofía que, en aquel momento, tenía que encontrar un nuevo puesto junto a la nueva física habían asegurado, con lo mental, un nuevo ámbito objetual y, con la introspección, un método propio. Además, la fílosofía podía entenderse a sí misma como disciplina fundamental que controla y justifica los fundamentos de todas las demás ciencias. Y Rorty piensa que idéntica autocomprensión fundamentalista se apodera de la filosofía del lenguaje cuando ésta retrocede ante una comprensión contextualista del conocimiento y la justificación. De esta sospecha se hacen acreedores los planteamientos universalistas de la filosofía del lenguaje como el que Rorty descubre, por ejemplo, cn Dummett.

Rorty (1981), p. 422.

1" Rorty (1981), p. 200: La concepciôn contextualista «amenaza la concepción neokantiana de la relación de la filosofía con las ciencias y con la cultura en su totalidad. El afán en decir que las afirmaciones y las acciones no pueden ser simplemente coherentes con otras afirmaciones, sino que además tendrían que corresponder con algo que es independiente de lo que las personas dicen y hacen, puede ser descrito con razón como el impulso fílosófico por excelencia.»

Rorty (1981), p. 191. 


\section{Contextualismo y escepticismo como problemas especificos de un paradigma}

Cuando Rorty contempla el contextualismo como consecuencia necesaria de la culminación del giro lingüístico, en cierto sentido tiene razón: el contextualismo designa un problema que sólo puede aparecer cuando contamos con una razón encarnada en la práctica lingüística. Pero se equivoca cuando, al mismo tiempo, entiende el contextualismo como la solución a este problema. Esta concepción tiene sus raíces, si estoy en lo cierto, en una problemática comprensión de los paradigmas filosóficos.

Rorty considera también (al igual que Apel o Tugendhat) la historia de la filosofía como una sucesión de tres paradigmas. Habla de la metafísica, de la teoría del conocimiento y de la filosofia del lenguaje ${ }^{12}$. Sin embargo, la filosofía del lenguaje sólo se ha desprendido a medias del mentalismo; Rorty cree que el giro lingüístico sólo puede proseguirse consecuentemente en forma de una crítica de la razón que conduce fuera de la filosofía en cuanto tal. En definitiva, el subtítulo de La filosofía y el espejo de la naturaleza reza así: Una crítica de la filosofía. No sólo los problemas, sino también el tipo de planteamientos cambia con el salto de un paradigma al próximo: «Es cierto que el esquema según el cual la filosofía antigua y medieval se interesaba por las cosas, la filosofia del siglo XVIr por las ideas y la ilustrada escena contemporánea por las palabras, tiene una plausibilidad notable. Pero no deberíamos creer que esta sucesión ofrece tres concepciones contrapuestas sobre lo primario o el fundamento. No se trata de que Aristóteles creyera poder explicar mejor las ideas y las palabras con el esquema conceptual de las cosas, y que Descartes y Russell cambiaran la dirección de la explicación. Sería más correcto decir que Aristóteles ni disponía de una teoría del conocimiento ni vio ninguna necesidad de ello, y que Descartes y Locke no poseían ninguna teoria del significado. Las observaciones de Aristóteles no se nos ofrecen ni como buenas ni como malas respuestas a las preguntas de Locke, de la misma forma que las observaciones de Locke sobre el lenguaje no dan respuesta alguna a las preguntas de Frege ${ }^{13}$. Esta discontinuidad significa que las cuestiones filosóficas no se solventan mediante respuestas correctas; más bien se dejan de lado una vez han perdido su valor. Esto vale también para la cuestión sobre la objetividad del conocimiento.

Según la concepción mentalista la objetividad queda asegurada cuando el sujeto representador se refiere de manera correcta a su objeto. Controla la subjetividad de sus representaciones en base al mundo objetivo: «El concepto "subjetivo" [es] lo contrario de "corresponde con lo que hay afuera" y, por

"Sabre esto, véase el artículo de H. Schnädelbach «Philosophie» en E. Martens y H. Schnädelbach, Grandkurs Philosophie, Hamburgo, 1985, pp. 37-76.

${ }^{13}$ Rorty (1981), p. 289. 
tanto, significa tanto como "es meramente el producto de aquello que ocurrc aquí dentro" " ${ }^{14}$. Según la concepción lingüística, la subjetividad de las creencias ya no se controla de manera inmediata confrontándolas con el mundo, sino mediante una coincidencia pública, alcanzada en la comunidad de comunicación: «Una reflexión "subjetiva" es aquella que tendría que (...) ser dejada de lado por los otros participantes racionales en el diálogo» ${ }^{15}$. Con ello, la intersubjetividad del entendimiento sustituye la objetividad de la experiencia. La relación lenguaje-mundo se convierte en dependiente de la comunicación entre hablante y oyente. La referencia vertical al mundo de las representaciones de, o de los enunciados sobre algo, se flexiona por decirlo así hasta la referencia horizontal del «con otros» propia de los participantes en la comunicación. La intersubjetividad del mundo de la vida que los sujetos habitan conjuntamente desplaza la objetividad de un mundo frente al que se halla un sujeto solitario: «Para los pragmatistas el deseo de objetividad no es el deseo de huir de las limitaciones de la propia comunidad, sino simplemente el deseo de coincidencia intersubjetiva lo más amplia posible» ${ }^{16}$. Rorty quiere decir: el cambio de paradigma transforma la perspectiva de tal forma que las cuestiones epistemológicas como tales están passé.

La comprensión contextualista del giro lingüístico del que surge este antirrealismo se remite a una concepción del ascenso y el ocaso de los paradigmas que excluye tanto la continuidad de los temas como los procesos de aprendizaje que traspasen los límites de los paradigmas. Efectivamente, los conceptos bajo los cuales acometemos una comparación entre paradigmas reflejan la situación hermenéutica de partida y, con ello, el propio paradigma. Quc Rorty elija para ello el marco de referencia de la objetividad, la subjetividad y la intersubjetividad es algo que resulta de la perspectiva conceptual de fondo a partir de la cual hemos descrito el giro lingüístico del mentalismo. Por otra parte, esta descripción no concuerda con la imagen de una sucesión contingente dc paradigmas inconmensurables entre ellos. El paradigma siguiente es más bien la respuesta a un problema que la devaluación del paradigma anterior nos ha legado. Los paradigmas no constituyen ninguna sucesión accidental, como piensa Rorty, sino que se encuentran en una relación dialéctica entre ellos.

El nominalismo había despojado a las cosas de su naturaleza interna y había proclamado los conceptos universales como construcciones del espíritu finito. Desde entonces la aprehensión mental del ente se vio carente de fundamentación en la constitución conceptual del ente mismo. La correspondencia de la mente con la naturaleza ya no podía concebirse como una relación del

is Rorty (1981), p. 368.

"Ibid.

16 R. Rorty, Solidarität oder Objektivität? Stuttgart, 1988, pp. 14 y \&. («isolidaridad u objetividad?», en R. Rorty, Objetividad, relativismo y verdad. Escritos filosóficos 1, Barcelona, Paidós, 1996). 
ser: las reglas de la lógica dejaron de refiejar las leyes de la realidad. El mentalismo, según Rorty, contestó a este reto invirtiendo la dirección de la cxplicación. Si el sujeto cognoscente ya no puede obtener los criterios del conocimiento de una naturaleza que ha perdido sus cualidades tiene que extraerlos de la subjetividad misma que se le abre mediante la reflexión. La razón, cncarnada objetivamente en el orden de la naturaleza, se recluye en el espíritu subjetivo. Con ello el «en sì del mundo se transforma en la objetividad de un mundo dado para nosotros, los sujetos; un mundo de objetos representados o que se nos aparecen. Así como, hasta entonces, la constitución de un mundo en sí había posibilitado una correspondencia de las ideas con la realidad - juicios verdaderos - a partir de ahora la verdad de los juicios debería medirse por la certeza de vivencias evidentes. El pensamiento representador conduce al conocimiento objetivo en tanto que aprehende el mundo que aparece.

Con el concepto de subjetividad se introdujo un dualismo entre interioridad y exterioridad que parecía poner al espíritu humano ante la difícil tarea de tener que salvar un abismo. Se abrían así las puertas para la moderna forma de escepticismo. El carácter privado de cada una de mis vivencias, sobre las que se apoya mi absoluta certeza, ofrece al mismo tiempo razones para dudar de si el mundo, tal como nos aparece, no será sólo una ilusión. Este escepticismo cstá anclado cn los conceptos paradigmáticos fundamentales del mentalismo. Conjura al mismo tiempo el recuerdo de aquella intuición tranquilizadora de la que había vivido el paradigma ontológico: que la verdad de los juicios está garantizada por una correspondencia con la realidad - correspondencia fundada ella misma en la realidad-. Esta intuición «suspendida», por decirlo asi, que a pesar del cambio de paradigma no había perdido en absoluto su capacidad de sugestión, se unió con la nueva pregunta escéptica de si $-\mathrm{y}$ dado el caso, cómo- habría que fundamentar, a partir de la evidencia de nuestras vivencias, la correspondencia entre el objeto y su representación. Y fue esta cuestión la que alimentó la disputa epistemológica entre idealismo y empirismo ${ }^{17}$. Sin embargo, a la luz de esta genealogía se muestra (y esto cs lo que me importa) que el contextualismo está tan profundamente cnraizado en los conceptos fundamentales del paradigma lingüístico como el escepticismo en los del mentalismo. Y de nuevo, las intuiciones sobre la verdad provenientes de paradigmas anteriores - y que permanecían ahí, suspendidas-- condujeron a agudizar esta problemática.

De la misma forma que, a fines de la Edad Media, la disputa de los universales contribuyó a la devaluación de la razón objetiva, en las postrimerías del siglo xix la crítica a la introspección y el psicologismo supuso una verdadera conmoción para la razón subjetiva. Al trasladar la razón desde la conciencia

"Sólo los empiristas estaban dispuestos a denominar como «objetiva" aquella experiencia que sse corresponde con aquello que hay en el exteriorm (Rorty), mientras que los idealistas trascendentales remitian todavía la objetividad de la experiencia a las condiciones subjetivas necesarias de la experiencia posible. 
del sujeto cognoscente al lenguaje - como aquel medio que utilizan los sujetos que actúan para comunicarse entre cllos- vuclve a cambiar de sentido la dirección de la explicación. La autoridad epistémica pasa del sujeto cognoscente (que extrae de sí mismo los criterios para la objetividad de la experiencia) a la praxis de justificación de una comunidad de lenguaje. Hasta entonces la validez intersubjetiva de las creencias resultaba de la convergencia a posteriori de las ideas o representaciones. Y la coincidencia interpersonal se explicaba partiendo del anclaje ontológico de los juicios verdaderos o en base a la dotación psicológica o trascendental de los sujetos cognoscentes. Pero después del giro lingüístico todas las explicaciones parten de la primacía de un lenguaje común. La descripción de estados y situaciones y de lo que sucede en el mundo objetivo, igual como la autopresentación de las vivencias subjetivas - de acceso privilegiado- depende del uso interpretativo de un lenguaje común. Por eso la expresión «intersubjetivo» ya no se refiere al resultado de una convergencia observable de pensamientos o representaciones de distintas personas, sino al hecho de compartir previamente una precomprensión lingüistica o un horizonte del mundo de la vida dentro del cual los miembros de una comunidad de interpretación se encuentran ya antes de empezar a entenderse unos con otros sobre algo en el mundo (siendo esta precomprensión común algo que, desde la perspectiva de los participantes mismos, se presupone). De esta primacía de la intersubjetividad de creencias compartidas sobre la confrontación con una realidad (siempre ya interpretada) surge, en definitiva, la problemática contextualista, que no debe confundirse con la duda epistemológica del escepticismo.

El giro pragmático no deja espacio para la duda sobre la existencia de un mundo independiente de nuestras descripciones. Antes bien, desde Peirce hasta Wittgenstein, la duda cartesiana - que gira en el vacío- ha sido refutada como contradicción realizativa: «Quien quisiera dudar de todo, no llegaría ni tan sólo a la duda. El mismo juego de la duda presupone ya la certeza» ${ }^{18}$. Por otra parte, todo saber es falible $y$, en caso de problematización, precisa de justificación. Tan pronto como el criterio para la objetividad del conocimiento pasa de la certeza privada a la práctica pública de la justificación, la "verdad» se convierte en un concepto trivalente. La validez de enunciados básicamente falibles se prueba como validez fundada para un público ${ }^{19}$. Y dado que en el paradigma lingüístico las verdades sólo son accesibles en forma de lo racionalmente aceptable, se plantea ahora la cuestión de cómo puede aislarse entonces la vcrdad de un enunciado del contexto de su justificación. La inquietud que produce este problema concita viejas intuiciones sobre la verdad y despierta el recuerdo de la correspondencia entre las ideas y la realidad o el contacto cierto de los sentidos con ella. Estas imágenes - que a pesar de haber perdido

Wittgenstein, Sobre la centeza, Barcelona, Gedisa, 1987, \$115.

${ }^{2}$ H. Schnädelbach, «Thesen über Geltung und Wahrheit», en Zur Rehabilitierung des animal rational, Francfort del Meno, 1992, pp. 104-115. 
su valor continúan siendo sugestivas - se encuentran detrás de la cuestión de cómo compatibilizar la circunstancia de que no podemos trascender el horizonte lingüístico de nuestras creencias justificadas con la intuición de que los enunciados verdaderos se ajustan a los hechos. No es casual que el debate actual sobre la racionalidad gire en torno a los conceptos de verdad y referencia ${ }^{21}$. Del mismo modo que el escepticismo no asimila simplemente el Ser a la Apariencia, sino que expresa la inquietud que nos produciría el no poder ser capaces de separar de modo convincente lo uno de lo otro, tampoco el contextualismo bien entendido equipara la verdad a la aseverabilidad justificada. El contextualismo es más bien expresión de la perplejidad que surgiría si tuvićramos que asimilar to uno a to otro. El contextualismo trae a conciencia un problema para el cual el relativismo cultural presenta una solución que incurre en contradicción realizativa y es, por tanto, falsa.

\section{Verdad y justificación}

Incluso en la comprensión de enunciados elementales relativos a estados o sucesos en el mundo, el lenguaje y la rcalidad se interpenetran de una forma que, para nosotros, es indisoluble. No existe ninguna posibilidad natural de aislar las limitaciones de la realidad que hacen verdadero un enunciado, de las reglas semánticas que establecen las condiciones de verdad del mismo. Sólo podemos explicar lo que es un hecho con ayuda de la verdad de un enunciado sobre hechos; y lo que es real sólo podemos explicarlo en conceptos de lo que es verdadero. Ser es, como dice Tugendhat, ser veritativo ${ }^{2 !}$. Y dado que la verdad de las creencias o de las oraciones, a su vez, sólo puede fundamentarse con ayuda de otras creencias y oraciones, no podemos escapar del círculo de nuestro lenguaje. Esta circunstancia sugiere un concepto antifundamentalista del conocimiento y un concepto holista de justificación. Dado que no podemos confrontar nuestras oraciones con nada que no esté, cllo mismo, impregnado lingüísticamente, no pueden distinguirse enunciados básicos que tuvieran el privilegio de legitimarse por sí mismos y pudieran servir como base de una cadena lineal de fundamentación. Rorty destaca, con razón, «que algo sirve como justificación sólo en relación a algo distinto que ya aceptamos», y de ello concluye aque saliéndonos de nuestro lenguaje y de nuestras creencias no podemos llegar a obtener un test criterial que sea independiente del criterio de la coherencia de nuestras afirmaciones» ${ }^{22}$.

Con respecto a la crítica al planteamiento de Rorty me limitaré, en lo que sigue, a la problemática de la verdad. Sin embargo, quisiera señalar al menos que no podriamos explicar la posibilidad de procesos de aprendizaje sin la capacidad de reconocer las mismas entidades bajo diferentes descripciones.

:E. Tugendhat, Einfukrung in die sprachanalytische Philosophie, Francfort, 1976, pp. 66 y s.

$\therefore$ Rorly (1981), pp. 199 y s. 
Sin embargo, esto no significa que la coherencia de nuestras creencias sea suficiente para explicar el significado del concepto de verdad - que ha devenido central - Cierto que, dentro del paradigma lingüístico, la verdad de un enunciado ya no puede concebirse como la correspondencia con algo en el mundo, pues entonces tendríamos que poder "salirnos del lenguaje» con el lenguaje. Evidentemente no podemos comparar la expresión lingüística con un trozo de realidad «desnuda» o no interpretada, es decir, con un referente que se sustraiga a nuestra inspección siempre presa de lo lingüistico ${ }^{23}$. Pero el concepto de correspondencia podía dar cuenta, a pesar de todo, de un aspecto significativo esencial del predicado de verdad; y este aspecto de validez incondicional se pasa por alto cuando se concibe la verdad de un enunciado como coherencia con otros cnunciados o como aseverabilidad justificada dentro de un sistema articulado de afirmaciones. En tanto que las afirmaciones bien justificadas pueden acabar mostrándose falsas, entendemos la verdad como una propiedad que los enunciados no pueden perder. La coherencia depende de prácticas de justificación que pueden guiarse ahora por un criterio y después por otro. De ahí la pregunta: «¿Por qué el hecho de que nuestras creencias dependan unas de otras, suponiendo que sea así, ofrece el menor indicio de que son verdaderas? ${ }^{24}$.

El uso «cautelar» del predicado de verdad ${ }^{25}$ muestra que, con la verdad de los enunciados, vinculamos una pretensión incondicional que apunta más allá de todas las evidencias disponibles; por otra parte, las evidencias que hacemos valer en nuestro contexto de justificación tendrían que ser suficientes para autorizarnos a mantener pretensiones de verdad. Aunque la verdad no puede reducirse a la coherencia y a la aseverabilidad justificada, debe haber una relación interna entre verdad y justificación. Si no, ¿cómo podría explicarse que una - según nuestros criterios - correcta justificación de «p» abonara la verdad de «p», a pesar de que la verdad no es ningún concepto «de éxito» y no depende de lo bien que un enunciado pueda justificarse? Michael Williams describe cl problema como la colisión entre dos ideas igualmente convincentes: «Primero, que si hemos de tener conocimiento de un mundo objetivo, la verdad de lo que creemos sobre el mundo debe ser independiente de nuestro creer en ello; y, segundo, que la justificación es inevitablemente una cuestión de dar soportc a las creencias mediante otras creencias y, por tanto, en este sentido mínimo, una cuestión de coherencia» ${ }^{26}$. De ahí resulta la pregunta contex-

"Véase M. Williams (1996), p. 232; «Sólo necesitamos preguntar si la aprehensión "directa" de hechos de la que depende tal comparación se supone que es un estado cognitivo con contenido proposicional o no. Si no lo es, no puede tener impacto alguno sobre la verificación. Pero si lo es, todo lo que se nos ha dado es otro tipo de creencia.»

2+ Williams (1996), p. 267.

" R. Rorty, «Pragmatism, Davidson and Truth», en E. Lepore (ed.), Truth and Interpretation, Londres, 1986, p. 343 («Pragmatismo, Davidson y la verdad», en R. Rorty, Objetividad, relativismo y verdad, Barcelona, Paidós, 1996, pp. 173-205).

Wh Williams (1996), p. 266. 
tualista: «dado sólo el conocimiento de lo que creemos sobre el mundo, y el modo como nuestras creencias se adecuan entre ellas, ¿cómo podemos mostrar que es probable que estas creencias sean verdaderas? ${ }^{27}$.

De todos modos, esta cucstión no debe entenderse en un sentido escéptico. Pues la concepción según la cual, como individuos socializados que somos, nos encontramos siempre ya en el horizonte lingüisticamente abierto de nuestro mundo de la vida, implica un trasfondo incuestionado de convicciones intersubjetivamente compartidas y prácticamente acreditadas que hacen que una duda total respecto a la accesibilidad del mundo sea algo sin sentido. El lenguaje - del que «no podemos salirnos»- no puede entenderse de modo análogo a la interioridad de un sujeto representador que está radicalmente separado del mundo exterior de los objetos representables. La relación que necesita ser aclarada cntre la posibilidad de justificación y la verdad no apunta a una brecha entre lo interior y lo exterior ni a ningún dualismo que tuviera que superarse y que pudiera despertar la pregunta escéptica de si nuestro mundo es, en su totalidad, una jlusión. El giro pragmático le quita toda base a este escepticismo. La razón es muy simple: en la práctica cotidiana no podemos utilizar el lenguaje sin actuar. El habla misma tiene lugar en el modo de actos de habla que, a su vez, están insertos en plexos de interacción y están entrelazados con accioncs instrumentales. En tanto que actores, es decir, como sujetos que interactúan e intervienen en el mundo, estamos ya en contacto con cosas sobre las que podemos hacer enunciados. Los juegos del lenguaje y las prácticas están entretejidos unos con otras: «En algún momento... tenemos que abandonar el ámbito de las oraciones (y de los textos) y recurrir a la concordancia con la acción y la experiencia (por ejemplo al usar un predicado) ${ }^{28}$. Desde un punto de vista de filosofía del lenguaje sc confirma el hallazgo fenomenológico de Husserl de que «estamos siempre ya con las cosas».

Es por cllo que la cuestión relativa a la rclación interna entre justificación y verdad - que explica por qué a la luz de las evidencias disponibles podemos plantear una pretensión de verdad que apunta más allá de aquello que está justificado- no es una cuestión epistemológica. No se trata del ser o de la apariencia. Lo que está en juego no es la representación correcta de la realidad, sino una práctica que no puede quebrarse. La inquietud contextualista denota la prcocupación por el correcto funcionamiento de las prácticas y los jucgos del lenguaje. El entendimiento (Verständigung) no puede funcionar sin que los participantes se refieran a un único mundo objetivo y con ello estabilicen el espacio público intersubjetivamente compartido del que puede diferenciarse todo lo meramente subjetivo ${ }^{29}$. La suposición de un mundo objetivo inde-

Wiliams (1996), p. 249.

"F. Kambartel, «Universalität, richtig verstanden», Deusche Zeitschrifl fär Philosophie, 44, 1996, p. 249.

${ }^{2}$ No por casualidad he introducido el concepto pragmatico-formal de la presuposición gramatical de un mundo objetivo en un contexto de teoría de la acción. Véase al respecto J. Habermas, 
pendiente de nuestras descripciones satisface una exigencia funcional de nuestros procesos de cooperación y entendimiento. Sin esta suposición se desintegraría una práctica que descansa en la distinción (en cierta forma) platónica entre opinión y saber inobjetable ${ }^{30}$. Si resultara que no podemos ni tan sólo efectuar esta distinción, la consecuencia sería más bien una autocomprensión patológica y errónea que una comprensión del mundo ilusoria. Mientras que el cscepticismo recela de un error epistemológico, el contextualismo sospecha de un defecto de construcción en nuestra forma de vivir.

El contextualismo plantea la cuestión de si - y, dado el caso, cómo- puede mantenerse en cl paradigma lingüístico la intuición de que podemos distinguir, en principio, entre «ser verdadero» y «tener por verdadero». Esta intuición no es «realista» en sentido epistemológico. También dentro del pragmatismo hay división de opiniones frente a esta cuestión. Unos son lo bastante pragmatistas para tomarse en serio la intuición cotidiana $-\mathrm{y}$ la relación interna que ella atestigua entre coherencia y verdad-. Otros consideran que el intento de aclarar esta relación no ofrece ninguna probabilidad de éxito y tratan el realismo cotidiano como una ilusión. Rorty quisiera luchar retóricamente contra esta ilusión y aboga por la reeducación. Según él, tendríamos que acostumbrarnos a sustituir nuestro deseo de objetividad por el deseo de solidaridad y, siguiendo a William James, no entender la «verdad» más que como aquello en lo quc, para "nosotros», miembros liberales de la cultura y las sociedades occidentales, es bueno creer: «[los pragmatistas] deberían verse a sí mismos como trabajando en conexión con el sentido común de su comunidad, un sentido común muy influenciado por la metafísica griega y el monoteísmo patriarcal... Deberían verse a sí mismos como dedicados a un intento a largo plazo de cambiar la retórica, el sentido común y la autoimagen de su comunidad» ${ }^{31}$.

Antes de entrar en esta propuesta, quiero examinar si las alternativas ofrecen tan pocas posibilidades de éxito como Rorty supone. ¿Seguro que no hay explicaciones plausibles para sostener que una justificación acertada - siempre dentro de nuestro contexto- habla en favor de la verdad -independiente del contexto- del enunciado justificado? Me interesan sobre todo dos intentos de explicación: el deflacionista, que combate que la «verdad» tenga en absoluto una naturaleza que pueda ser explicitada, y el epistémico que hincha tanto el concepto de afirmación justificada que la verdad se convierte en la magnitud límite del proceso de justificación. Por supuesto que el deflacionismo sólo puede destematizar el concepto de verdad hasta un punto en el que todavia

Theorie des kommunikativen Handeins, Francfort del Meno, 1981, vol, 1, pp. 114-151, asi como vol. 2, pp. 183 y ss. (Teoría de la acción comunicativa, Madrid, Taurus, 1987).

* Véase Williams (1996): p. 238: «Todo lo implicado en la idea del mundo objetivo como "lo que está ahí independientemente" es que el ser verdadera una proposición objetiva es una cosa y nuestro creer que es verdadera, o estar justificados en creer que es verdadera, es otra muy diferente.»

"R. Rorty, "Is Trutb a Goal of Enquiry? Davidson vs. Wright», Philosophical Quarterty, 45,1995 , pp. $281-300$, aquí p. 300. 
sea posible mantener una intuición realista; mientras que la concepción epistémica sólo puede idealizar las condiciones de justificación hasta el punto de que esta elevada argumentación se mantenga todavía al alcance de «nuestra» práctica ${ }^{32}$.

\section{El concepto semánico de verdad y la perspectiva pragmática}

La convención de la verdad de Tarski ", según la cual «"p" es verdadero si y sólo si p», se apoya en el uso desentrecomillador del predicado de verdad, que puede ilustrarse en base al ejemplo de la confirmación de enunciados formulados por terceros: «Todo lo que el testigo dijo ayer, es verdadero." El hablante hace propio «todo lo dicho» en tanto que podría repetir la afirmación correspondiente en posición de primera persona. Este uso del predicado de yerdad es interesante en dos sentidos. Por una parte permite referirse, de modo generalizador, a contenidos que se mencionan, pero que no se ofrecen de forma explícita; Tarski utiliza esta propiedad para construir una teoría generalizadora de la verdad que vaya más allá de todas las ocurrencias de "V». Por otra parte, el predicado de verdad establece, en este uso, una relación de equivalencia entre dos expresiones lingüísticas; ahí reside toda la gracia

"D. Davidson persigue una tercera estrategia que podría denominarse teoreticista o, como él mismo proponc, umctodológica»; véase D. Davidson, "The Folly of Trying to define Truth", The Joumal of Philosopty, XCIII, 1996, pp. 263-278. Davidson utiliza el concepto semántico de verdad entendido no deflacionistamente como un concepto no definido, fundamental para una teoría empírica del lenguaje. Al mismo tiempo, con esta teoría - que quiere explicar la comprensión de las expresiones linguísticas- se puede acreditar el concepto de verdad utilizado en ella como término teórico. Por eso la implicita eteoria de la verdad* de Davidson sólo puede discutirse cn el contexto de la totalidad de su teoría. En general veo la siguiente dificultad: por un lado, Davidson rechaza que el concepto de verdad tenga un contenido que pueda scr explicado y sc adhiere por tanto a la polémica deflacionista contra los intentos de explicar el sentido de la verdad; por otro lado, sin embargo, debe asegurar al predicado de verdad, más allá de su función desentrecomilladora, un cierto contenido - -n términos de teoría de la racionalidad- a fin de poder explicar la naturaleza veritativa de las creencias. En esta medida, se adhiere a Putnam y Dummet, que sostienen firmemente que la convención " $T$ » no expresa nada sobre el auténtico sentido de la verdad. Situado entre estas dos posiciones, Davidson, en lugar de limitarse a utilizar un concepto que él mismo ha declarado «indefinible», se ve empujado a escribir instructivos trabajos en los que, no obstante 10 anterior, va dando siempre vueltas, de forma metacrítica, a la intuición realista vinculada a la verdad. Vid. D. Davidson, "The Structure and Content of Truths, The Joumat of Philosophy, LXXXVII, 1990, pp. 279-328. Respecto a ello Davidson mantiene que podemos saber algo de un mundo objetivo que nosotros mismos no hemos hecho (awhich is not of our own making»). Esta idea le separa de Rorty, que intenta sin éxito atraer a Davidson hacia el lado de su propia comprensión abolicionista de la verdad. Vid. D. Davidson, «A Coherence Theory of Truth and Knowledgew, en Malachowski (ed.), Reading Rorty, Oxford, 1990, pp. 120-139, así como Rorty (1996). Sobre la comparación entre Davidson y mi planteamiento en términos de teoria del lenguje, vid. B. Fultner, Radical Interpretation or Communicative Action, Tesis doctoral, Northwestern University, Evanston, Ill., 1995.

*N.T.: Citada, en adelante, como *convención "T""s. 
de la estrategia tarskiana. Al emplear la función desentrecomilladora puede reproducirse, como se ve, la inaccesible arelación de correspondencia» entre lenguaje y mundo - u oración y hecho - en el nivel de la evidente relación semántica entre expresiones de un lenguaje objeto y de un metalenguaje. Con independencia de cómo imaginemos la función expositiva de los enunciados -ya sea como «satisfacción» de condiciones de verdad o como «adecuación» de los hechos a las oraciones - siempre se nos hacen presentes imágenes de relaciones que van más allá del lenguaje y éstas no parece que puedan explicarse solamente por medio de nexos intralingüisticos. Esta idea inicial nos hace comprender por qué el concepto semántico de verdad va ligado a débiles connotaciones realistas, aunque está claro que tal concepto no puede soportar un realismo à la Popper ${ }^{33}$.

Pronto se señaló que el concepto semántico de verdad no puede hacer efectiva la pretensión de explicar su significado ${ }^{34}$. Esto se explica por el hecho de que la función desentrecomilladora no es lo suficientemente informativa, puesto que presupone ya la función expositiva. Comprendemos el sentido de la convención « $T$ » porque ya sabemos to que significa la parte derecha del bicondicional. El sentido del predicado en la oración «Todo lo que el testigo dijo ayer, es verdadero» es parasitario del modo asertórico de las afirmaciones hechas por el testigo. Antes de que una afirmación pucda ser citada, debe ser «formulada». Este sentido asertórico puede analizarse ejemplarmente en las tomas de posición afirmativas o negativas de los participantes en una argumentación cuando formulan o rechazan objeciones; o también en aquel uso «cautelar» del predicado de verdad que nos recuerda la experiencia -que todo participante en argumentaciones ha hecho- de que incluso enunciados convincentemente justificados pueden mostrarse finalmente como falsos.

El predicado de verdad forma parte - aunque no sólo- del juego de lenguaje de la argumentación; por ello su significado puede aclararse - al menos también- en base a sus funciones dentro de este juego de lenguaje, es decir, en la dimensión pragmática de una determinada utilización del predicado. Quien se limita a la dimensión semántica (tanto de las oraciones como de los comentarios metalingüísticos a las oraciones) aprehende solamente el reflejo de una práctica lingüística previa que, como se demostrará, llega hasta la práctica cotidiana. De todas formas, el tratamiento deflacionista del concepto de verdad extrae una ventaja del enmascaramiento semántico del sentido pragmático de la verdad: con ello se pueden cludir discusiones sobre la «naturaleza» de la verdad, sin tener que abandonar la orientación, aunque sea mínima, por la

${ }^{* 3}$ K. R. Popper, aTruth, Rationality, and the Growth of Scientific Knowledgcs, cn K. R. Popper, Conjecures and Refutations, Londres, 1963, pp. 215-250 (versión española: Conjetumas y refutaciones, Barcelona, Paidós, 1994).

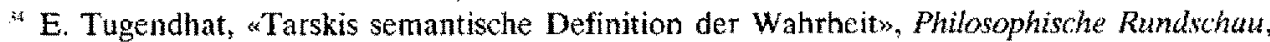
8, 1960, pp. 131-159, impreso de nuevo en E. Tugendhat, Philosophische Aufsötze, Francfort del Meno, 1992, pp. 179-213. 
distinción entre saber y creer, entre «ser verdadero» y «tener por verdadero». La estrategia apunta a mantener separadas estas distinciones elementales de la disputa relativa a concepciones epistemológicas sustanciales. Si se puede mostrar que el concepto semántico de verdad es suficiente para explicar los métodos habituales de investigación y de elección de teorías, es decir, para explicar también lo que en la actividad científica cuenta como un «logro» o un «incremento de saber», podremos salvar - sin una carga epistémico-realista del concepto de verdad - la suposición débilmente realista de un mundo independiente de nuestras descripciones ${ }^{35}$.

Por otra parte, la ciencia no es el único ámbito -ni siquiera el primeroen el que se usa el predicado de verdad. Incluso si el concepto deflacionista de verdad fuera suficiente para explicar el factum de la ciencia y hacer así transparente el funcionamiento de nucstra práctica investigadora, la duda contextualista todavía no se habría disipado. Pues ésta se extiende no solamente a la construcción y elección de teorías, ni tampoco sólo a la práctica argumentativa en general. En relación a las orientaciones a la verdad preteóricas que se producen en la práctica cotidiana, el concepto semántico de verdad no ayuda para nada.

En el mundo de la vida nos encontramos con el papel pragmático de una verdad con rostro jánico, que media entre la certeza de acción y la aseverabilidad discursivamente justificada. En la red de prácticas habituales, las pretensiones de validez implícitamente sostenidas - y que son aceptadas ante un amplio trasfondo de convicciones intersubjetivamente compartidas - forman, por así decirlo, las vías por las que discurren aqucllas certezas que dirigen la acción. Sin embargo, tan pronto como pierden su respaldo en la estructura de estas evidencias, las certezas quebradas se transforman en otras tantas dudas que, de esta forma, se convierten en tema de discusión. En el tránsito de la acción al discurso ${ }^{36}$, lo que inicialmente $-y$ de forma ingenua- se había tenido-por-verdadero se desliga del modo de una certeza de acción y toma la forma de un enunciado hipotético cuya validez se planteará en el discurso. La argumentación tiene la forma de una pugna en torno a los mejores argumentos en favor o en contra de la pretensión de validez controvertida y sirve a la búsqueda cooperativa de la verdad ${ }^{37}$.

Pero con esta descripción de una práctica de justificación orientada a la verdad se plantea de nuevo el problema de cómo la movilización sistemática de buenas razones que, en el mejor de los casos, conduce a creencias justificadas puede al mismo tiempo bastar para discriminar entre pretensiones de verdad

"Con referencia a posiciones de $P$. Horwich y A. Fine, véase M. Williams, «Do We (Epistcmologists) need a Thcory of Truth?", Philosophical Topics, XIV, 1986, pp. 223-242.

- Introduje esta distinción en las Christian Gauss Lectures sobre la fundamentación de la sociología en términos de filosofia del lenguaje. Véase J. Habermas, Vorstudien und Ergänzungen zur Theorie des kommunikativen Handelns, Francfort del Meno, 1983, pp. 1-126, en especial pp. 104 y ss. (Teoria de la acción comunicativa: complementos y estudios previos, Madrid, Cátedra, 1989).

J. Habermas (1981), vol. 1, pp. 44-71. 
justificadas y no justificadas. De entrada quisiera sólo atenerme a la imagen del proceso circular que la perspectiva ampliada en términos de teoría de la acción nos ofrece: las certezas de acción que se han visto problematizadas se transforman en el plano argumentativo en controvertidas pretensiones de validez para enunciados hipotéticos; éstas se examinan discursivamente y, dado el caso, se hacen efectivas, de modo que, ya como verdades aceptadas, pueden volver al contexto de acción; con ello, pueden producirse de nuevo (si se da el caso) otras certezas de acción que se apoyan en lo que, aproblemáticamente, se tiene-por-verdadero. Lo que sigue precisando explicación es la enigmática fuerza del acuerdo logrado por medios discursivos que autoriza a los participantes en la argumentación, en su papel de actores, a aceptar sin reservas como verdades las afirmaciones justificadas. Pues cuando cl asunto se describe en términos de teoría de la acción resulta claro que la argumentación solamente puede cumplir el papel de eliminar perturbaciones de las certezas de acción que han devenido problemáticas si nos guíamos por la verdad entendida en un sentido independiente del contexto, esto es, por la verdad en sentido incondicional.

Aunque en actitud reflexiva sabemos que todo saber es falible, en la vida cotidiana no podemos vivir solamente con hipótesis, es decir, no podemos vivir en todo momento falibilistamente. El falibilismo organizado de la investigación puede mantener continuamente un tratamiento hipotético de pretensiones de verdad controvertidas porque sirve a una proceso de obtención de consenso desacoplado de la acción. Este no es un modelo para el mundo de la vida. Sin duda tenemos que tomar decisiones en base a informaciones incompletas y los riesgos existenciales como la pérdida de parientes cercanos, la enfermedad, la vejez y la muerte son la divisa de la vida humana. Pero las rutinas cotidianas descansan, al margen de estas inseguridades, en la confianza sin reservas tanto en el saber de los legos como de los expertos. No cruzaríamos ningún puente, no utilizaríamos ningún automóvil, no nos someteríamos a operación alguna y ni tan sólo tomaríamos una comida exquisitamente preparada si no estuviéramos seguros de los conocimientos puestos en práctica y no tuviéramos por verdaderos los supuestos utilizados en su producción y ejecución. La necesidad realizativa de certezas de acción excluye en cualquier caso una reserva de principio frente a la verdad, a pesar de que sabemos, tan pronto como se nos hacen añicos los resultados de la acción ingenuamente presupuestos, que las pretensiones de verdad sólo pueden desempeñarse discursivamente dentro del contexto de justificación correspondiente. La verdad no puede asimilarse ni a la certeza de acción ni a la aseverabilidad justificada. Resulta claro que sólo unos conceptos fuertes de saber y verdad -que son reos de platonismo- pueden hacer justicia a la unidad del sentido ilocucionario de las afirmaciones, las cuales adoptan distintos papeles según se hallen en acciones o en discursos. Mientras que en la praxis las «verdades» afianzan certezas de acción, en el discurso ofrecen el punto de referencia para las pretensiones de verdad. 


\section{El concepto epistémico de verdad en perspectiva pragmática}

El arduo problema de la relación entre verdad y justificación hace que sea comprensible el intento de distinguir «verdad» de «aceptabilidad racional» mediante una idealización de las condiciones de justificación. En virtud de ello un enunciado justificado en base a «nuestros» criterios se diferencia de un enunciado verdadero de la misma forma que un enunciado justificado en el contexto correspondiente se distingue de aquel que podría justificarse en todos los contextos. Llamamos averdadero» a un enunciado que podría justificarse bajo condiciones epistémicas ideales (Putnam) ${ }^{38}$, o que en una situación ideal de habla (Habermas) ${ }^{39} \longrightarrow$ en una comunidad ideal de comunicación (Apel) - ${ }^{40}$ encontraría un acuerdo alcanzado por medios argumentativos. Verdadero es aquello que puede ser racionalmente aceptado bajo condiciones ideales. Contra esta propuesta, que se retrotrae hasta Peirce, se han formulado convincentes objeciones. Algunas se dirigen a las dificultades conceptuales relacionadas con el supuesto estadio ideal; otras muestran que una idealización de las condiciones de justificación no puede satisfacer su objetivo, ya que tal idealización o bien separa demasiado la verdad de la aseverabilidad justificada o las separa demasiado poco.

El primer tipo de objeciones señala la naturaleza paradójica de un saber "completo» o «definitivo» planteado como magnitud límite que, al ser desposeído de su falibilidad o de su necesidad de ser complementado, dejaría de ser un saber (humano) ${ }^{4 !}$. También es paradójica la idea de un consenso último o de un lenguaje definitivo que paralizarían toda comunicación o interpretación posterior — «de modo que lo que se piensa como situación de entendimiento ideal, se revela como una situación más allá de la necesidad ( $\mathrm{y}$ de los problemas) del entendimiento lingüístico»- ${ }^{42}$. Esta objeción se dirige no sólo contra una idealización que hipostatiza aquellas situaciones o estadios finales convirtiéndolos en estadios alcanzables. Incluso si los puntos de referencia ideales no se entienden en principio como objetivos alcanzables $\rightarrow 0$ se entienden así sólo aproximativamente - se mantiene «la paradoja de que estaríamos obligados a perseguir la realización de un ideal cuyo cumplimiento

* H. Putnam, Realism and Reason, Cambridge University Press, 1983, Introducción.

"J. Habermas, «Wahrheitstheorien» (1972), en J. Habermas (1983), pp. 127-186.

"K. O. Apel, «Fallibilismus, Konsenstheorie der Wahrheit und Letzbegründung", en Forum für Philosophie (ed.), Philosophic und Begründung, Francfort del Meno, 1987, pp. 116-211 («Falibilismo, teoria consensual de la verdad y fundamentación última», en K. O. Apel, Teoría de la veriad y ética del discurso, Barcelona, Paidós, 1991).

${ }^{4}$ C. Lafont, «Spannungen in Wahrheitsbegriff», Deutsche Zeitschrift für Philosophie, 42, 1994, pp. 1007-1023 («Dilemas en torno a la verdad», Theoria, 23, 1995, pp. 109-124); Williams (1996), pp. 233 y ss.

${ }_{22}$ A. Wellmer, Ethik und Dialog, Francfort del Meno, 1986, p. 91 (Éca y diálogo, Barcelona. Anthropos, 1994). 
seria el fin de la historia humanas ${ }^{43}$. El sentido crítico de la orientación a la verdad como una idca regulativa resulta claro precisamente cuando se idealizan las propicdades formales o procesuales de la argumentación, no sus objetivos.

A la misma conclusión conducen las objeciones del segundo tipo. Éstas se dirigen, no contra los resultados incoherentes de la idealización de la situación de llegada, sino contra la operación de idealización misma. Con independencia de cómo se sobrevaloren, idealizándolas, las condiciones epistémicas, o bien satisfacen el carácter incondicionado de las pretensiones de verdad mediante exigencias que imposibilitan todo contacto con las prácticas de justificación que nos son conocidas; o bien mantienen el vínculo con una práctica que conocemos, pero al precio de que la aceptabilidad racional, incluso bajo estas condiciones ideales, no deja entonces de excluir el error, es decir, no supone ninguna propiedad que los enunciados no puedan perder: «resultaría evidente que o bien estas condiciones permiten la posibilidad de error o son tan ideales que no sirven para lograr la buscada conexión con las capacidades humanas» ${ }^{44}$

En la discusión con Putnam y conmigo, Rorty no utiliza estas objeciones para desacreditar la epistemologización de la verdad, sino más bien para radicalizarla. Rorty comparte con sus oponentes la idea de que los criterios para la aceptabilidad racional de los enunciados, aunque cambian históricamente, no lo hacen en cada caso de forma arbitraria; los estándares de racionalidad son accesibles a la crítica - en cualquier caso desde la perspectiva de los participantes-y pueden ser "reformados», es decir, pueden mejorarse por buenas razones. Sin embargo, Rorty se niega, a diferencia de Putnam, a dar cuenta del hecho del «poder aprender» mediante la aceptación de que la praxis de justificación se orienta por una idea de verdad que va más allá del contexto correspondiente de justificación. Rorty rechaza totalmente conceptos límite de carácter idealizador e interpreta la diferencia entre justificación y verdad de tal manera que el proponente está siempre dispuesto a defender sus puntos de vista no tan sólo ahora y aquí, sino incluso también ante un público distinto. Quien se orienta hacia la verdad en este sentido está dispuesto «a justificar sus convicciones ante un público competente» o «a ampliar el tamaño y la diversidad de la comunidad de diálogo" ${ }^{45}$. Según la concepción de Rorty toda idealización que vaya más allá ticne que fracasar por el hecho de que al idealizar siempre tenemos que partir de algo conocido, por regla general de «nosotros», es decir, de la comunidad de comunicación tal como la conocemos: «No alcanzo a ver lo que "aceptabilidad racional idealizada" puede significar, excepto que signifique "aceptabilidad para una comunidad ideal". Ni alcanzo a ver, dado

4 A. Wellmer, "Wahtheit, Kontingenz, Moderne», en A. Wellmer, Endspiele, Francfort del Meno, 1993, p. 162 (Finales de partida. La modemidad irreconciliable, Madrid, Cátedra, 1996).

* Davidson, "The Structure and Content of Truth», 1990, p. 307

45 R. Rorty, "Sind Aussagen universelle Geltungsansprüche?", en Deutsche Zeitschrift für Philosophie, 42, 1994, pp. 982 y s. 
que ninguna comunidad de este tipo va a disponer del punto de vista del ojo de Dios, que esta comunidad ideal pueda ser otra cosa que nosotros tal como deberíamos ser. Ni alcanzo a ver lo que "nosotros" puede significar aparte de: nosotros, liberales educados, sofisticados, tolerantes y antiprohibicionistas, el tipo de gente que está siempre dispuesta a escuchar a la otra parte, a sopesar todas sus implicaciones, etc. ${ }^{\text {th }}$.

Contra ello puede sin duda oponerse que una idealización de las condiciones de justificación no tiene que partir, en absoluto, de las propiedades «fuertes» de la cultura propia correspondiente, sino que puede plantearse en general desde las propicdades formales y procesuales de las prácticas de justificación que están extendidas en todas las culturas - si bien no siempre en forma institucionalizada-. Ello se ve favorccido por la circunstancia de que la praxis de la argumentación obliga a los participantes mismos a hacer presuposiciones pragmáticas de contenido contrafáctico. Quien entra en una discusión con la intención seria de convencerse de algo en diálogo con otros, tiene que suponer, en términos realizativos, que los participantes decidirán su «sí» o su «no" únicamente mediante la fuerza del mejor argumento. Pero con ello suponen, normalmente de forma contrafáctica, una situación de diálogo que satisface condiciones poco probables: apertura al público e inclusión, participación iguafitaria, inmunización frente a coacciones externas o internas, así como orientación al entendimicnto de todos los participantes (es decir, expresiones sinceras) ${ }^{47}$. En estas includibles presuposiciones de la argumentación sc expresa la intuición de que los enunciados verdaderos son resistentes frente a los intentos de impugnación, sin ningún tipo de limitación espacial, social o temporal. Aquello que tenemos por verdadero tiene que poder defenderse con razones convincentes no sólo en otro contexto, sino en todos los contextos posibles, es decir, en todo momento y frente a cualquiera. Ahí es donde se inspira la teoría discursiva de la verdad: un enunciado es verdadero si, bajo las exigentes condiciones de un discurso racional, puede resistir todos los intentos de refutación ${ }^{49}$.

Esto no significa que también por eso sea verdadero. Una pretensión de verdad que se ha hecho valer para «p» indica que las condiciones de verdad de «p» están satisfechas. Si éste es el caso o no, es algo que sólo podemos comprobar en el curso de la argumentación, ya que nos está vedado el acceso directo a condiciones de verdad no interpretadas. Pero la circunstancia de que las condiciones de verdad estén satisfechas no se convierte de por sí en una circunstancia epistémica por el hecho de que el desempeño discursivo de la pretensión de verdad sea la única vía para poder comprobar si estas condiciones (que tenemos que interpretar siempre a la luz del tipo de razones apropiadas al caso) están satisfechas.

h. Rorty, Putnan (1993), pp. 451 y s.

F. J. Habermas, Erläuteningen zur Diskursethik, Francfort del Meno, 1991, pp. 131 y ss. y $164 \mathrm{ys}$.

"L. Wingert, Gemeinsinn und Moral, Francfort del Meno, 1993, p. 277. 
Una lectura epistémica consecuente de la explicación de la verdad en términos de la teoría del discurso fracasa ya por el hecho mismo de que no todas las propiedades procesuales mencionadas mantienen "conexión con capacidades humanas». De presuposiciones de la argumentación tales como inclusión, participación igualitaria, libertad de coacciones y orientación al entendimiento podemos al menos imaginar en la actualidad una satisfacción idealmente aproximativa. Esto no vale respecto a una anticipación de futuro o de una acreditación venidera. Sin duda que también esta orientación tiene esencialmente el sentido crítico de recordarnos la limitación etnocéntrica y la falibilidad del acuerdo logrado en cada caso y motivado racionalmente (por los medios que fuerc) - es decir, de hacernos presente, en definitiva, el descentramiento progresivo del punto de vista de nuestra comunidad de justificación-. Pero el tiempo es una limitación de tipo ontológico. Dado que todos los discursos reales que se desarrollan en el tiempo son limitados respecto al futuro, no podemos saber si los enunciados que hoy, incluso bajo condiciones ideales aproximativas, son racionalmente aceptables se sostendrán en cl futuro frente a los intentos de refutación. Por otra parte, esta limitación condena a nuestra mente finita a darse por satisfecha con la aceptabilidad racional como una prueba suficiente de la verdad: "siempre que sostenemos pretensiones de verdad en base a buenos argumentos y evidencias convincentes suponemos... que en el futuro no aparecerán nuevos argumentos o evidencias que pongan en cuestión nuestra pretensión de verdad» ${ }^{49}$

Por qué los participantes en la argumentación, en tanto que sujetos capaces de lenguaje y acción, tienen que comportarse así, es algo no muy difícil de comprender si se parte de una descripción pragmática de su discurso, siempre inserto en el mundo de la vida. En la praxis, como hemos visto, los individuos socializados dependen de certezas de acción que sólo permanecen como certezas en tanto que se alimentan de un saber aceptado sin reservas. A ello corresponde el hecho gramatical de que, cuando planteamos la afirmación «p» en actitud realizativa, tenemos que pensar que " $\mathrm{p}$ » es incondicionalmente verdadero, a pesar de que, en actitud reflexiva, no excluyamos que mañana o en otro lugar pueden aparecer razones y evidencias que refuten «p». Sin embargo, con ello no se ha explicado todavía por qué podemos considerar desempeñada una pretensión de verdad explícitamente sostenida para "p", tan pronto como el enunciado ha sido aceptado racionalmente bajo las condiciones del discurso. ¿Qué significa que las pretensiones de validez pueden «desempeñarse» discursivamente?

"Wellmer (1993), p. 163; vid. las reflexiones correspondientes sobre la «superaseverabilidad" por parte de C. Wright, Truth and Objectivity, Harvard U. P., Cambridge, Mass., 1992. 


\section{El concepto pragmático de verdad}

Todavía no está claro qué nos autoriza a mantener como verdadero un enunciado que, en los límites de una mente finita, suponemos idealmente justificado. En este contexto Wellmer habla de un "plus» (Überschuß $\beta$ ) contenido en la "anticipación de acreditación futura». Quizá deberíamos decir mejor que los participantes en la argumentación que se convencen de la justificación de una pretensión de validez han llegado a un punto en el que son llevados a un cambio de perspectiva mediante la coacción sin coacciones del mejor argumento. Cuando los participantes, en el curso de un proceso de argumentación, llegan a la convicción de que, conociendo todas las informaciones oportunas y después de ponderar todas las razones relevantes, han agotado el potencial de posibles objeciones contra «p», ya no quedan motivos para una prosecución de la argumentación. En cualquier caso ya no hay ningún motivo racional para continuar manteniendo una actitud hipotética frente a la pretensión de verdad sostenida respecto a «p» (pero temporalmente dejada en suspenso, como mera hipótesis). Desde la perspectiva de actores que a fin de volver a restablecer un acuerdo de fondo parcialmente alterado habían adoptado temporalmente una actitud reflexiva, la desproblematización de la pretensión de verdad discutida significa la licencia para una vuelta a la actitud de actores que están envueltos en un trato ingenuo con el mundo. Tan pronto como se han disipado las diferencias de opinión entre «nosotros» y los «otros» en relación a lo que es el caso, «nuestro» mundo puede fusionarse con «el» mundo.

En este momento crucial, a aquellos participantes en la argumentación a los que aceptamos como justificada su pretensión de verdad respecto a «p», les estamos restableciendo su derecho a plantear el hasta entonces problemático hecho - "que $\mathrm{p}$ "- como una afirmación «Mp» formulable en primera persona. Una afirmación que se ha desproblematizado así por medios argumentativos y ha sido devuelta al contexto de acción encuentra su lugar en un mundo de la vida intersubjetivamente compartido, desde cuyo horizonte nosotros, los actores, nos referimos a algo en el único mundo objetivo. De lo que se trata aquí es de una suposición formal que no prejuzga ningún contenido determinado ni nos sugiere tampoco aquella finalidad última de la «imagen correcta de la naturaleza y las cosas» que Rorty vincula continuamente con la intuición realista. Dado que los sujetos que actúan tienen que habérselas bien con «el» mundo, no pueden evitar ser realistas en cl contexto de su mundo de la vida. $\mathrm{Y}$, además, cstán autorizados para serlo, ya que sus juegos de lenguaje y sus prácticas, en tanto que funcionan como resistentes al desengaño, se «acreditan» en el mismo acto de su ejecución.

Esta instancia pragmática de cercioramiento - explicada en términos realistas con ayuda de la suposición de un mundo objetivo- está en suspenso en el plano reflexivo de los discursos; éstos están liberados de la acción y 
en ellos sólo cuentan los argumentos. Aquí la mirada se desvía, por decirlo así, del mundo objetivo - y de los desengaños que sufrimos al tratar con ćly se dirige exclusivamente a nuestras interpretaciones antagónicas sobre el mundo. En esta dimensión intersubjetiva de interpretaciones controvertidas, una afirmación se «acredita» solamente por medio de razones, es decir, en la instancia de las refutaciones posibles y no en la de los desengaños experimentados en la práctica. Aquí, la conciencia falibilista de que podemos equivocarnos incluso en los casos de creencias bien fundamentadas depende, por supuesto, de una orientación a la verdad que hunde sus raices en aquel realismo de la práctica cotidiana (un realismo que dentro del discurso queda en suspenso). La orientación a la verdad incondicional que obliga a los participantes en la argumentación a suponer condiciones ideales de justificación y los lleva a un descentramiento progresivo de su comunidad de justificación es un reflejo de aquella otra diferencia, indispensable en el mundo de la vida, entre creer y saber. Una diferencia que se apoya en la suposición, enraizada en el uso comunicativo del lenguaje, de un mundo objetivo único ${ }^{50}$. De esta forma el mundo de la vida, con sus fuertes conceptos de verdad y de saber (conceptos ligados a la acción), se adentra en el discurso y ofrece aquel punto de referencia que trasciende la justificación y que mantiene despierta entre los participantes en la argumentación la conciencia de la falibilidad de nuestras interpretaciones. En contrapartida, esta conciencia falibilista repercute también en la práctica, sin destruir por ello el dogmatismo del mundo de la vida. Pues los actores que, como participantes en la argumentación, han hecho la experiencia de que ninguna convicción está segura ante la crítica, desarrollan también en el mundo de la vida una actitud más bien no-dogmática frente a aquellas de sus convicciones que han devenido problemáticas.

La percepción estereoscópica de los procesos de cooperación y entendimiento -estratificados en plexos de acción y discursos- nos deja ver que los discursos están insertos en el mundo de la vida. En la acción las convicciones juegan un papel distinto que en el discurso y se «acreditan» de forma distinta en un sitio y en el otro. En la praxis es aquel prerreflexivo «habérselas bien con el mundo» lo que decide si las convicciones «funcionan» o caen en el remolino de la problematización, mientras que en la argumentación, el hecho de que la pretensión de validez controvertida merezca o no un reconocimiento racionalmente motivado es algo que depende solamente de razones. Es cierto que la cuestión relativa al nexo interno entre justificación y verdad sólo se plantea en este plano reflexivo; pero tan sólo la interacción entre acciones y discursos permite dar respuesta a esta cuestión. La duda contextualista no podrá eliminarse si nos mantenemos aferrados al plano argumentativo sin atender a la transformación que se produce del saber de los que actúan al saber

"Vid. Cristina Lafont (1994), p. 1021: «Sólo la presuposición de un mundo objetivo único (...) nos permite compatibilizar la validez incondicional de la verdad con el carácter falible que atribuimos a nuestro saber.» 
de los que argumentan (una transformación asegurada, por decirlo así, por la unidad personal); pero tampoco se eliminará si ignoramos la transferencia de saber que se produce en dirección contraria. Sólo el entrecruzamiento de estos dos roles pragmáticos distintos -que pone en juego, en plexos de acción y en discursos, aquel concepto de verdad «de rostro jánico»- puede explicar por qué una justificación lograda en nuestro contexto habla en favor de la verdad (independiente del contexto) de la creencia justificada. De la misma forma que, de un lado, el concepto de verdad permite la traducción de certezas de acción quebradas en enunciados problematizados, el mantenimiento de una orientación a la verdad permite, por otro lado, la retraducción de afirmaciones discursivamente justificadas en renovadas certezas de acción.

Para esta explicación tenemos aún que combinar correctamente los distintos enunciados parciales reunidos hasta ahora. En el mundo de la vida los actores dependen de las certezas de acción. Tienen que habérselas bien con un mundo que se supone objetivo y por ello tienen que operar con la distinción entre creer y saber ${ }^{51}$. Existe la necesidad práctica de confiar intuitivamente en lo que incondicionalmante es tenido-por-verdadero. Este modo de lo incondicionalmente tenido-por-verdadero se refleja en cl plano discursivo en las connotaciones de las pretensiones de verdad, las cuales apuntan más allá del contexto de justificación existente en cada caso y obligan a hacer la suposición de condiciones ideales de justificación - con la consecuencia de un descentramiento de la comunidad de justificación-. Por eso el proceso de justificación puede orientarse a una verdad que aun trascendiendo el contexto, sin embargo es siempre operativa en la acción. La función de validez de los enunciados en la práctica cotidiana explica por qué la resolución discursiva de pretensiones

${ }^{3}$ En el presente contexto no puedo entrar a analizar el caso de las pretensiones de validez morales u otras pretensiones de validez normativas sometidas a desempeño discursivo. A éstas les falta aquella trascendencia respecto a la justificación que las pretensiones de verdad ostentan a causa de la suposición - establecida en el uso comunicativo del lenguaje - de un mundo objetivo único. Las pretensiones de validez normativas se hacen valer para relaciones interpersonales que tienen lugar en un mundo social que no es de la misma forma independiente de «nuestro hacer» como lo es el mundo objetjvo. Pero su tratamiento discursivo es «análogo a la verdad» en tanto que los participantes en el discurso práctico se orientan por el objetivo de «una única respuesta correcta» - sea un mandato, un permiso o una prohibición-. El mundo social es intrínsecamente histórico, es decir, constituido ontológicamente de modo distinto que el mundo objetivo. Por ello la idealización de las condiciones de justificación no pueden incluir aquí una «anticipación de acreditación futuram en el sentido de una refutación anticipada de objeciones futuras (Wingert), sino que sólo puede ser entendida en el sentido critico de una «reserva de aproximación", es decir, de una reserva frente al estado al que ha llegado actualmente el descentramiento de la comunidad de justificación. El desempeño discursivo de una pretensión de verdad significa que las condiciones de verdad interpretadas como condiciones de asevcrabilidad cstán satisfechas. En el caso de pretensiones de validez normativas, el acuerdo alcanzado discursivamente fundamenta el reconocimiento de la norma correspondiente $-y$, cn esta medida, contribuye él mismo a la satisfacción de las condiciones de validez de la norma-. Mientras que la aceptabilidad racional solamente indica la verdad de un enunciado, en el caso de las normas presta una contribución constructiva a su validez. 
de validez puede ser interpretada como satisfacción de una necesidad pragmática de justificación. Esta necesidad de justificación que pone en marcha la transformación de certezas de acción quebradas en pretensiones de validez problematizadas, sólo puede ser satisfecha, sin embargo, mediante la retraducción de las creencias discursivamente justificadas en verdades que orientan la acción.

Como esta interacción es la que, en definitiva, destruye la duda contextualista respecto a la intuición realista cotidiana, es fácil objetar que con la descripción tendenciosa de los discursos insertos en el mundo de la vida se está prejuzgando toda la cuestión en disputa. Sin duda Rorty no negaría cl nexo entre discurso y acción. También estaría de acuerdo en que establecemos un nexo entre ambas perspectivas - entre el punto de vista de los participantes en la argumentación-, que intentan convencerse mutuamente de sus interpretaciones y la perspectiva de sujetos que actúan, involucrados en sus juegos de lenguaje y sus prácticas. Pero Rorty no diferenciaría estas perspectivas hasta el punto de que una se relativice en función de la otra. Para su descripción toma prestado del punto de vista de los participantes en la argumentación aquel «estar presos del diálogo» que nos impide escaparnos de los contextos de justificación; al mismo tiempo toma de la perspectiva de los actores el modo de cnfrentarse y habérselas bien con cl mundo. Mediante el oscurecimiento recíproco de estas dos perspectivas contrapuestas se forma entonces la certeza ctnocéntrica que induce a Rorty a plantear la pregunta de por qué debemos intentar armonizar en absoluto nuestra compresión contextualista - lograda mediante experiencias argumentativas- con aquel realismo cotidiano atribuido al mundo de la vida. Si los actores en el mundo de la vida - de momento - no pueden menos que ser "realistas", peor para ellos. Corresponde entonces a los filosofos reformar el erróneo concepto de verdad del sentido común.

Claro está que, para esta finalidad, un deflacionismo que opere con el concepto semántico de verdad - al modo de Michael Williams- es aún demasiado fuerte. En vez de ésto Rorty emprende de modo consecuente la epistemologización del concepto de verdad. Dado que sólo hay justificación y dado que de la aseverabilidad justificada de un enunciado no se sigue nada respecto a su verdad, el concepto de verdad es superfluo: «la diferencia entre justificación y verdad no es nada más que el aviso de que la justificación frente a una audiencia no es la justificación frente a otra» ${ }^{52}$. Incluso el único uso no redundante del predicado de verdad —el uso «cautelar»- precisa ser reinterpretado. Se trata de inventar e imponer un nuevo vocabulario que se las arregle sin el concepto de verdad y que haga desaparecer las intuiciones realistas (como la suposición de un mundo objetivo, hablar de la representación de hechos, etc.): «Simplementc rehusamos hablar de un modo determinado, de modo platónico (...). Nuestros esfuerzos de persuasión tienen que adoptar la forma de una

\footnotetext{
"Rorty, «Is Truth a Goal to Enquiry?», 1996, p. 300.
} 
inculuación gradual de nuevos modos de hablar, más que la forma de argumentación sincera con los viejos modos» ${ }^{53}$.

\section{La naturalización de la razón lingüistizada}

El programa de reeducación rortyano ha provocado preguntas y objeciones ${ }^{54}$. En primera línea, compete a Rorty la carga probatoria de su no querer dejar cl lenguaje del sentido común tal y como es. Los pragmatistas hacen generalmente mucho alarde de que sus concepciones concuerdan con el sentido común. Los neopragmatistas se vanaglorian, curiosamente, de jugar el papel de «atcos en una cultura dominantemente religiosa». Su terapia sobre los patológicos juegos de lenguaje de los filósofos debe llegar hasta las deformaciones que el platonismo ha causado en la vida cotidiana misma. A fin de hacer plausible el contenido idealista de tales deformaciones Rorty tiene que emprender el diagnóstico de la decadencia de la metafísica occidental. Pero lo que Heidegger o Derrida, por ejemplo, dicen - de modo bastante metafísico, por cicrto-sobre la crítica de la metafísica, pertenece más bien, según la propia valoración de Rorty, a aquella literatura «edificante» que debe mantenerse reservada al perfeccionamiento privado y que, en cualquier caso, no puede servir para criticar públicamente condiciones de vida alienadas ${ }^{55}$. Pero más importante que la motivación es sin duda la viabilidad del empeño. Sobre esto, y como conclusión, sólo dos preguntas: 1) ¿Es compatible la pretendida revisión de nuestra autocomprensión con el hecho de un «poder aprender» que no esté ya acotado a priori?; y 2) ¿En qué se convierte el carácter normativo de la razón y hasta qué punto resulta contraintuitiva la recomendada autocomprensión neodarwinista de seres racionales?

1) El programa de una revisión racional de prejuicios platónicos hondamente enraizados exige de nosotros un proceso de aprendizaje que no pucde discurrir solamente dentro de un vocabulario dado y conforme a los criterios existentes en cl contexto dado, sino que abarca el vocabulario y los criterios mismos. Ya por esta razón Rorty tiene que ofrecer un equivalente apropiado para aquella «orientación a la verdad» que apunta más allá del contexto de justificación existente. Pero si la difcrencia entre «verdadero» y ujustificado» se acorta hasta tal punto que el proponente está dispuesto a defender "p» incluso ante otro público, falta el punto de referencia para tal anticipación. p. 5

R. Rorty, «Relativism: Finding and Making» (manuscrito, 1995, de próxima publicación),

"Th. McCarthy, «Philosophie und gesellschaftliche Praxis. Richard Rortys" neuer Pragmatismus», Ideale und Illusionen, Francfort del Meno, 1993, pp. $19-51$ («Filosofía y práctica social: el "nuevo pragmatismo" de Richard Rorty", en McCarthy, Ideales e ilusiones, Madrid, Tecnos, 1992, pp. 21-50).

R. Rorty, "Habermas, Derrida, and the Function of Philosophy», Revue Intemationale de Philosophie, 49, 1995, pp. 437-460, y mi respuesta en las pp. 553-556. 
Rorty se enfrenta a esta objeción admitiendo una precavida idealización de las condiciones de justificación. Según él, lo que tradicionalmente se ha llamado «búsqueda de la verdad» podría ser descrito igual de bien como «búsqueda de un acuerdo intersubjetivo, sin coacciones, entre grupos de interlocutores cada vez más amplios»: «Esperamos justificar nuestra creencia frente a tantas y cuan más amplias audiencias posibles» ${ }^{56}$. Sin duda que Rorty no quiere que se entienda csto como un orientarse por un «objetivo que siempre va alejándose», es decir, como una idea regulativa. El público ampliado y el contexto más extenso no dejarán de ser solamente otro público y otro contexto. Sin embargo, Rorty añade a esta descripción las mencionadas cualificaciones de una progresiva extensión y un mayor número de audiencias; condiciones éstas que, en determinados aspectos no totalmente casuales, dificultan el éxito posible de la argumentación.

Rorty no puede explicar esta complicación - por otra parte innecesaria, visto pragmáticamente - Con la orientación a «más numerosas», «más amplias» y "más variadas» audiencias Rorty pone en juego una idealización débil que no resulta nada evidente. Tan pronto como se elimina el concepto de verdad en favor de una «validez para nosotros» de carácter epistémico y dependiente del contexto se echa en falta el punto de referencia normativo que explicaría por qué un proponente debería esforzarse en obtener un asentimiento para "p» más allá de las fronteras del propio grupo. El dato de que el asentimiento de un público cada vez mayor propicia que cada vez tengamos menos miedo a ser refutados presupone ya, precisamente, el interés que tendría que justificarse, a saber, el «deseo de acuerdo intersubjetivo lo más amplio posible». $\mathrm{Si}$ «verdadero» es justamente aquello que, porque es bueno «para nosotros», puede ser tenido como justificado "por nosotros", no existe motivo racional alguno para ensanchar el círculo de los miembros de nuestra comunidad de justificación. Falta entonces toda razón para una expansión descentradora de la comunidad de justificación, máxime cuando, como Rorty, se define el propio etnos como el grupo ante el cual me siento obligado a rendir cuentas. Sin embargo, para una orientación progresiva en dirección al asentimiento de «extraños» no existe ninguna justificación normativa, sino sólo la alusión explicativa a las eventuales propiedades de una «cultura occidental liberal» en la que «nosotros los intelectuales» adoptamos una actitud más o menos antidogmática. Pero incluso a nosotros, Rorty nos asegura "que en la práctica tenemos que preferir el propio grupo, a pesar de que no pueda haber ninguna justificación no circular de este modo de proceder» ${ }^{57}$.

2) Al perder la idea regulativa de la verdad, la práctica de la justificación pierde también aquel punto de orientación a través del cual los estándares de justificación pueden diferenciarse de las normas «de costumbre». La sociologización de la práctica de justificación significa una naturalización de la razón.

"Rorty, «Is Truth a Goal of Enquiry?», 1996, p. 298.

${ }^{57}$ Rorty, Solidarität oder Objektivität?, 1988, p. 26. 
En general las normas sociales pueden ser descritas no sólo desde el punto de vista de un observador sociológico, sino que pueden justificarse también desde la perspectiva de los participantes a la luz de los estándares que ellos mantienen como válidos. No obstante, sin su referencia a la verdad o a la razón, los estándares mismos no tendrían ninguna posibilidad de autocorrección y con ello perderían, por su parte, el estatus de normas justificables. Bajo este aspecto no serían ni tan sólo normas de costumbre. En ese caso no son nada más que hechos sociales, a pesar de que «para nosotros» -la comunidad de justificación relevante - sigan reclamando validez. Con todo, si la práctica de justificación no debe quebrarse y el predicado «racional» no ha de perder su carácter normativo, es decir, si ambos tienen que mantener su funcionalidad, entonces los estándares de racionalidad válidos para nosotros tienen que ser, si no justificados, al menos explicados.

Para ello Rorty recurre a la descripción naturalista de los humanos como seres vivos que desarrollan instrumentos a fin de satisfacer necesidades y adaptarse así, del mejor modo posible, a su entorno. El lenguaje es también un instrumento de este tipo y no un medio para la exposición de la realidad: «No importa si el instrumento es un martillo o un arma o una creencia o una afirmación, el uso de instrumentos es parte de la interacción del organismo con su entorno" ${ }^{58}$. Aquello que nos parece normativo de la mente humana lingǘsticamente constituida pone de manifiesto solamente que las operaciones inteligentes son funcionales para el mantenimiento de una especie que, al actuar, tiene que «habérselas bien» con el mundo. Esta autodescripción neodarwinista exige un precio irónico. Efectivamente, en tanto que sustituye la «descripción correcta de hechos" por una "adaptación eficaz al cntorno", Rorty intercambia un objetivismo por otro: el objetivismo de lo «representado» frente al objetivismo de la realidad instrumentalmente «dominada». Con ello, aunque cambia la dirección de la interacción entre el hombre y el mundo, no varía sin embargo el punto de referencia del mundo objetivo como la totalidad de aquello que podemos o bien «exponer» o bien «tratar».

El giro pragmático debía reemplazar el modelo representacionista del conocimiento mediante un modelo comunicativo que sustituyera la quimérica objetividad de la experiencia por un entendimiento intersubjetivo que se va logrando. Pero precisamente esta dimensión intersubjetiva se hace de nuevo innaccesible cuando se describen los procesos de cooperación y entendimiento de modo objetivante; unos procesos que, como tales, sólo pucden concebirse desde la perspectiva de los participantes. Rorty utiliza una jerga que no permite ya diferenciar entre las perspectivas del participante y del observador. Las relaciones interpersonales - que se deben al patrimonio intersubjetivo de un lenguaje común - son asimiladas al modelo del comportamiento adaptativo (o de la acción instrumental). Al no hacer las diferenciaciones correspondientes entre los usos estratégico y no estratégico del lenguaje, entre la acción orientada

\footnotetext{
${ }^{*}$ Rorty, «Finding and Making», 1995, pp. 11 y s.
} 
al éxito y la acción orientada al entendimiento, Rorty se priva de los medios conceptuales para dar cuenta, de forma correcta, de las distinciones intuitivas entre convencer y persuadir, entre la motivación mediante razones y la influencia causal, entre el aprendizaje y el indoctrinamiento. La confusión contraintuitiva de lo uno con lo otro tiene la desagradable consecuencia de que perdemos las pautas críticas que funcionan en la vida cotidiana. La estrategia naturalista de Rorty conduce a tal nivelación catcgorial que nuestras descripciones se hacen insensibles a unas distinciones que, en la práctica, marcan la diferencia ${ }^{59}$.

${ }^{39}$ El mismo objetivismo y el mismo tipo de falta de sensibilidad puede comprobarse en la descripción egocéntrica o etnocéntrica de los procesos de interpretación, por ejemplo en los difíciles casos de entendimiento intercultural. A diferencia de Gadamer, Rorty no recurre a las condiciones simetricas de adopción de una misma perspectiva -algo que tanto el hablante como el oyente han aprendido mediante la utilización del sistema de los pronombres personales y que hace posible una aproximación reciproca de los horizontes de interpretación inicialmente separados-. En su lugar, parte de una relación asimetrica entre «nosotros» y kellos», de modo que nosotros enjuiciamos sus manifestaciones según nuestros estándares y tenemos que equiparar sus estándares a los nuestros [vid. J. Habermas, Nachmetaphysisches Denken, Francfort del Meno, 1988, pp. 175 y ss. (Pensamiento postmetafisico, Madrict, Taurus, 1990 , pp. 176 y ss.)]. Este modelo asimilador de la comprensión (Verstehen) se acerca al modelo interpretativo de Davidson. Pero lo que en Davidson es consecuencia de una decisión metodológica - entender la interpretación de las expresiones linguísticas como utilización de hipótesis pertenecientes a una teoría de la verdad en clave empírica-, en Rorty resulta de una decisión de estrategia teórica que opta por un vocahulario descriptivo de caracter naturalista. 